http://jmscr.igmpublication.org/home/ ISSN (e)-2347-176x ISSN (p) 2455-0450 crossref DOI: https://dx.doi.org/10.18535/jmscr/v8i2.09

\title{
Inflammatory Myofibroblastic tumour masquerading as TCC
}

\author{
Authors \\ Dr Tejas M. Mistry ${ }^{1}$, Dr Pravin Ladda ${ }^{{ }^{*}}$, Dr Sujan Singh ${ }^{1}$, Dr Vikram Batra ${ }^{2}$, \\ Dr Sachin Kathuria ${ }^{2}$, Dr Ajay Sharma ${ }^{2}$ \\ ${ }^{1}$ Senior Resident, ${ }^{2}$ Consultant \\ Department of Urology, Sir Ganga Ram Hospital New Delhi, India \\ *Corresponding Author \\ Pravin Laddha
}

\section{Introduction \& Objective}

Inflammatory Myofibroblastic tumour (IFMT) or 'pseudotumour' of the kidney is a rare benign tumour . It affects mostly young adults. Clinical examination and radiological investigations are either inconclusive or suggest malignant lesion. Renal mass biopsy is often inconclusive which necessitates a management in the line of Renal Cell Cancer (RCC) or Transitional Cell Carcinoma (TCC) as per presentation. Definitve diagnosis is based on histopathological analysis of the specimen by using immunohistochemistry ${ }^{[1]}$. We are reporting a case of $16 \mathrm{yr}$ old female who presented with hematuria \& flank pain. Pre-op frozen section biopsy was done which was suggestive of transitional cell carcinoma. Radical nephroureterectomy was done \& the final diagnosis based on histopathology \& immunohistochemistry was turned out to be inflammatory myofibroblastic tumor of kidney.

\section{Methods}

A 16 year old female presented with complaint of mild dull aching pain in left flank area for 1 year.
She had an episode of gross painless hematuria without any clots 1 year back.

Her clinical examination was normal. Ultrasound of kidney \& urinary tract was done which was suggestive of left hydronephrosis and dilated upper ureter with no evidence of any stone. In view of the history of gross painless hematuria, a contrast enhanced CT scan was done. This was suggestive of a $2 \mathrm{~cm}$ sized well defined, heterogeneous, mildly enhancing mass lesion in left renal pelvis. Decision was made to have a preoperative diagnosis of the lesion as malignant tumor at such a young age was suspicious \& a radical surgery would have profound impact on her quality of life. Hence she was posted for the diagnostic biopsy. Initially flexible ureteroscopy was attempted. However, the ureter was narrow \& full of clots, so it couldn't be done. Then decision was made for percutaneous biopsy of the mass through a nephroscope. Tissue was sent for frozen section analysis. 


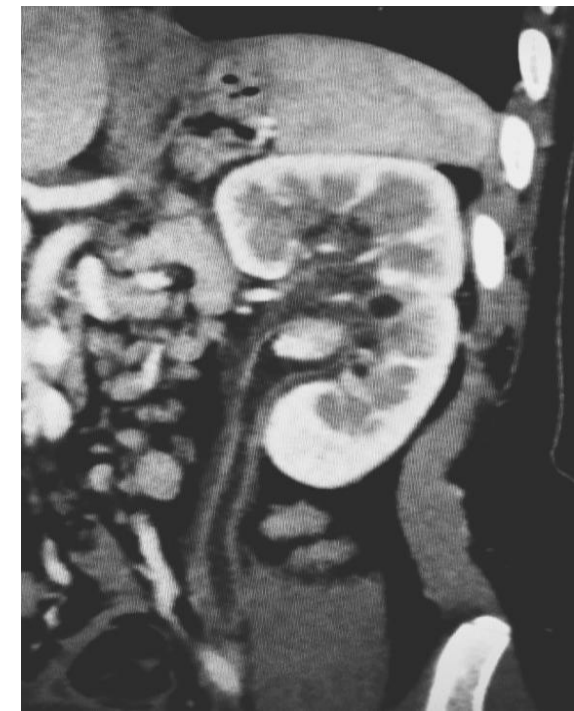

\section{Results}

Frozen section analysis was suggestive of transitional cell carcinoma. Relatives were counseled about proceeding to radical surgery. Left radical nephro-ureterectomy was done. Final diagnosis through histopathology \& immunhistochemistry was turned out to be inflammatory myofibroblastic tumor.
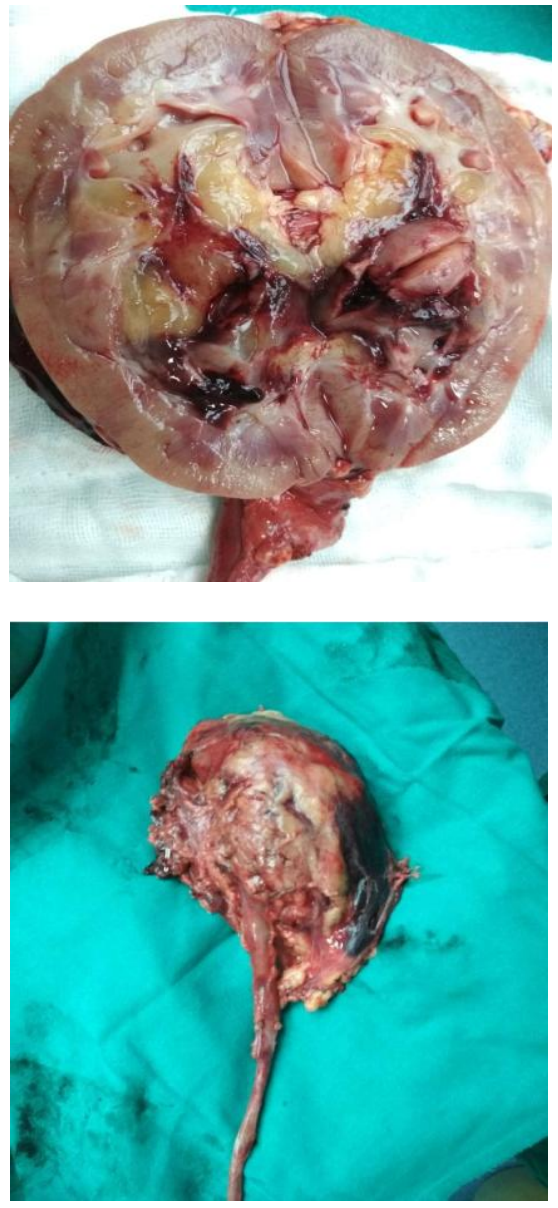

\section{Discussion}

Inflammatory Myofibroblastic Tumour (IFMT) is a rare tumor affecting young people of age 3 to 89. It's more common in males as compared to females. IFMT are common in lungs and orbit. IMT is common in the bladder in the urinary tract. In the literature, about 40 cases have been reported $^{[1]}$. The first IMT of the kidney was reported in 1972 by Davides et al., as plasma cell granuloma $^{[2]}$.

The exact cause is debatable as some suggest that it is a reactive process while others suggest it to be a true neoplasm. Possibe risk factors are surgery, trauma, irritation and infection due to EpsteinBarr virus and herpes virus. Translocation of chromosome band 2p23 involving ALK receptor tyrosine kinase gene suggest a neoplastic origin $[3,6]$.

Most common presentation is abdominal pain $(38 \%)$. About $36 \%$ of tumours are detected incidentally. Other symptoms include haematuria (28\%), constitutional symptoms (23\%) and occasionally a mass ${ }^{[1]}$. The radiological features of IFMT are non-specific. Many times the diagnosis is usually made pathologically after surgical removal. $85 \%$ of reported cases underwent partial or radical nephrectomy. There is one case of spontaneous regression on follow-up ${ }^{[4]}$. A case of IFMT enclosing renal cell cancer has also been reported necessitating careful consideration ${ }^{[1]}$.

Histopathologically, there is proliferation of spindle cells admixed with variable amounts of a lymphoplasmacytic infiltrate. Immunohistochemically, there is consistent expression of vimentin and smooth muscle actin. There is variable positivity has been identified for HHF-35, cytokeratins, and CD68. ${ }^{[1]}$

Recurrence of inflammatory pseudotumor in the urinary tract has not been reported. ${ }^{[9]}$ Coffin et al . concluded that ALK reactivity is a favorable prognostic indicator. ${ }^{[7]}$

For patients who are unfit for complete resection or if the tumor is unrespectable, other modalities like corticosteroid and nonsteroidal anti- 
inflammatory agents, radiation or chemotherapy have been suggested ${ }^{[5,8,9]}$

\section{Conclusion}

Patients presenting with gross hematuria \& renal pelvic mass need to be thoroughly evaluated by contrast enhanced CT scan or MRI. Inflammatory myofibroblastic tumor does not have any specific features on imaging. Frozen section analysis should not be relied upon, as it can be misleading. A better pre-operative diagnostic method in future would save patients with such benign tumors from radical surgeries $\&$ their morbidities.

\section{Bibliography}

1. Pothadiyil A. Inflammatory Myofibroblastic Tumor of the Kidney: A Rare Renal Tumor. Journal Of Clinical And Diagnostic Research. 2016;10(11).

2. Davides KC, Johnson SH, Marshall M, Price SE, Stavrides A. Plasma cell granuloma of the renal pelvis. J Urol. 1972;107(6):938-39.

3. Lawrence B, Perez-Atayde A, Hibbard MK, Rubin BP, Dal Cin P, Pinkus JL, et al. TPM3-ALK and TPM4-ALK oncogenes in inflammatory myofibroblastic tumours. Am J Pathol. 2000;157:377-84.

4. Marshall J, Lin EP, Bhatt S, Dogra VS. Inflammatory Pseudotumour of the Kidney. J Ultrasound Med. 2008;27:80307.

5. Ma Y, Zieske AW, Fenves AZ. Bilateral infiltrating renal inflammatory pseudotumour responsive to corticosteroid therapy. Am J Kidney Dis. 2008;51:11620.

6. Gleason BC, Hornick JL. Inflammatory myofibroblastic tumours: Where are we now? J Clin Pathol. 2008;61:428-37.
7. Coffin CM, Hornick JL, Fletcher CD. Inflammatory myofibroblastic tumor: Comparison of clinicopathologic, histologic, and immunohistochemical features including ALK expression in atypical and aggressive cases. Am J Surg Pathol 2007;31:509-20.

8. Chavez C, Hoffman MA. Complete remission of ALK-negative plasma cell granuloma (inflammatory myofibroblastic tumor) of the lung induced by celecoxib: A case report and review of the literature. Oncol Lett 2013;5:1672-6.10.

9. Kalpana KM, Babu P, Nagaraj H, Mysorekar V. Inflammatory pseudotumor of kidney masquerading as renal carcinoma. Journal of Cancer Research and Therapeutics. 2015;11(3):668. 